\title{
Blunted Feedback Suppression of SREBP Processing by Dietary Cholesterol in Transgenic Mice Expressing Sterol-Resistant SCAP(D443N)
}

\author{
Bobby S. Korn, ${ }^{*}$ lichiro Shimomura, ${ }^{*}$ Yuriy Bashmakov, ${ }^{*}$ Robert E. Hammer, ${ }^{\S}$ Jay D. Horton, ${ }^{\star}$ Joseph L. Goldstein, ${ }^{\star}$ \\ and Michael S. Brown* \\ ${ }^{*}$ Department of Molecular Genetics, ${ }^{\ddagger}$ Department of Biochemistry, and ${ }^{\S}$ Howard Hughes Medical Institute, University of Texas \\ Southwestern Medical Center, Dallas, Texas 75235
}

\begin{abstract}
Feedback regulation of cholesterol biosynthesis is mediated by membrane-bound transcription factors designated sterol regulatory element-binding proteins (SREBP)-1 and -2. In sterol-deprived cultured cells, SREBPs are released from membranes by a proteolytic process that is stimulated by SREBP cleavage-activating protein (SCAP), a membrane protein containing a sterol-sensing domain. Sterols suppress SREBP cleavage by blocking the action of SCAP, thereby decreasing cholesterol synthesis. A point mutation in $\mathrm{SCAP}(\mathrm{D} 443 \mathrm{~N})$ causes resistance to sterol suppression. In this article, we produced transgenic mice that express mutant SCAP(D443N) in liver. In these livers the nuclear content of SREBP-1 and -2 was increased, mRNAs encoding proteins involved in uptake and synthesis of cholesterol and fatty acids were elevated, and the livers were engorged with cholesteryl esters and triglycerides enriched in monounsaturated fatty acids. When the mice were challenged with a high cholesterol diet, cleavage of SREBP-1 and -2 was reduced in wild-type livers and less so in transgenic livers. We conclude that SCAP(D443N) stimulates proteolytic processing of native SREBPs in liver and decreases the normal sterol-mediated feedback regulation of SREBP cleavage, suggesting a central role for SCAP as a sterol sensor in liver. $(J$. Clin. Invest. 1998. 102:2050-2060.) Key words: cholesterol • fatty acids - sterol regulatory element-binding proteins • SCAP • transgenic mice
\end{abstract}

\section{Introduction}

Feedback regulation of cholesterol synthesis ensures that cells have adequate amounts of cholesterol for membranes and other cellular functions while preventing overproduction. Such regulation was first observed over 45 years ago when dogs were fed a high cholesterol diet, and cholesterol synthesis was found to be suppressed in liver (1). This was the first example of end-product feedback repression of a biosynthetic pathway

Address correspondence to Joseph L. Goldstein and Michael S. Brown, Department of Molecular Genetics, University of Texas Southwestern Medical Center, 5323 Harry Hines Blvd., Rm. L5.238, Dallas, TX 75235-9046. Phone: 214-648-2141; FAX: 214-648-8804; E-mail: jgolds@mednet.swmed.edu,mbrow1@mednet.swmed.edu

Received for publication 25 September 1998 and accepted in revised form 22 October 1998.

J. Clin. Invest.

(C) The American Society for Clinical Investigation, Inc. 0021-9738/98/12/2050/11 \$2.00

Volume 102, Number 12, December 1998, 2050-2060

http://www.jci.org in animals and is attributable in large part to sterol-mediated suppression of genes encoding multiple enzymes in the cholesterol biosynthetic pathway. This regulation is mediated by transcription factors called sterol regulatory element-binding proteins (SREBPs, ${ }^{1}$ reference 2 ).

SREBPs are produced as membrane-bound precursors of $\sim 1,150$ amino acids that contain three domains. The $\mathrm{NH}_{2}-$ terminal domain of $\sim 480$ amino acids is a transcription factor belonging to the basic helix-loop-helix leucine zipper (bHLHZip) family. The second domain of $\sim 80$ amino acids comprises two membrane-spanning regions separated by a short hydrophilic loop of 31 amino acids. This is followed by a COOH-terminal regulatory domain of $\sim 590$ amino acids. The SREBPs are oriented in a hairpin fashion such that the $\mathrm{NH}_{2}$ and $\mathrm{COOH}$-terminal domains project into the cytosol, and the hydrophilic loop faces the lumen of the endoplasmic reticu$\operatorname{lum}(2)$.

The mechanism for the regulation of SREBP activity was elucidated through studies in cultured cells (2). When cells are deprived of sterols, SREBPs are activated by a two-step proteolytic cascade. Processing begins when a protease (site 1 protease) clips SREBPs in the hydrophilic luminal loop, allowing the $\mathrm{NH}_{2}$ - and $\mathrm{COOH}$-terminal segments to separate (3). Once the two segments are separated, a second protease (site 2 protease) cuts the $\mathrm{NH}_{2}$-terminal segment at site 2 within the first transmembrane segment, allowing the $\mathrm{NH}_{2}$-terminal domain to leave the membrane (4). The cleaved $\mathrm{NH}_{2}$-terminal domain, known as nuclear SREBP (nSREBP), binds to the promoters and activates the transcription of genes encoding enzymes of cholesterol biosynthesis (3-hydroxy-3-methylglutaryl CoA [HMG CoA] reductase, HMG CoA synthase, farnesyl diphosphate synthase, squalene synthase, and others) and the low density lipoprotein (LDL) receptor $(2,5-8)$. nSREBPs also activate the transcription of genes encoding enzymes of fatty acid synthesis, including acetyl CoA carboxylase, fatty acid synthase, and stearoyl CoA desaturase (SCD), and at least one gene involved in phospholipid and triglyceride synthesis, glycerol-3-phosphate acyltransferase (9-14). Feedback regulation of cholesterol synthesis occurs at the level of SREBP proteolysis (15). When sterols accumulate in cells, cleavage of SREBPs at site 1 is abolished, SREBPs remain membrane bound, and transcription of all target genes declines (2).

1. Abbreviations used in this paper: GAPDH, glyceraldehyde-3-phosphate dehydrogenase; GLC, gas-liquid chromatography; GPAT, glycerol-3-phosphate acyltransferase; HMG CoA, 3-hydroxy-3-methylglutaryl CoA; HSV, herpes simplex virus; LDL, low density lipoprotein; nSREBP, cleaved nuclear form of SREBP; PEPCK, phosphoenolpyruvate carboxykinase; SCAP, SREBP cleavage-activating protein; SCD, stearoyl CoA desaturase; SREBP, sterol regulatory element-binding protein; $\mathrm{Tg}$, transgenic. 
In cultured cells, sterols regulate the cleavage of SREBPs by controlling the activity of a polytopic membrane protein designated SREBP cleavage-activating protein (SCAP; reference 16). SCAP is an intrinsic membrane protein with two domains. The $\mathrm{NH}_{2}$-terminal 730 amino acids contain alternating hydrophobic and hydrophilic sequences that are believed to span the membrane eight times (17). The COOH-terminal 546 amino acids contain five iterations of a motif known as the WD-40 repeat. WD repeats, found in many different proteins, mediate protein-protein interactions (18). The WD repeats of SCAP form a complex with the $\mathrm{COOH}$-terminal regulatory domain of SREBPs (19). This complex is essential for site 1 cleavage. Sterols inhibit the action of SCAP, thereby inhibiting SREBP cleavage $(16,19)$.

Sequence analysis of membrane-spanning segments 2-6 of SCAP reveals homology to three other proteins thought to interact with sterols: HMG CoA reductase, the Niemann-Pick C1 gene product, and the morphogen Patched (20). In HMG $\mathrm{CoA}$ reductase, the membrane attachment domain is responsible for rapid degradation of the protein when cells accumulate sterols $(21,22)$. A deletion of membrane spanning segments 2-6 in HMG CoA reductase abolishes sterol-stimulated degradation (21). The resemblance of the putative sterol-sensing domain of SCAP to HMG CoA reductase suggests that this domain of SCAP may serve as a sterol sensor that regulates cleavage of SREBPs (16).

SCAP was identified by expression cloning from 25-RA cells, a mutant line of Chinese hamster ovary (CHO) cells (23) that fail to suppress cleavage of SREBPs in the presence of sterols (16). The mutant SCAP produced in 25-RA cells contains an asparagine substituted for aspartic acid at residue 443, which lies within the sterol-sensing domain of SCAP. The D443N mutation is dominant and enhances the ability of SCAP to stimulate cleavage of SREBPs in cultured cells. Moreover, cells expressing SCAP(D443N) show a reduced ability to repress the cleavage of SREBPs in the presence of sterols, suggesting that the sterol-sensing domain of SCAP mediates feedback repression of SREBP processing (16). The mRNA for SCAP is expressed in the liver and other tissues, but it is not known whether SCAP regulates SREBP processing in these organs. The availability of a dominant, superactive mutant of SCAP provides a tool to address this question in mice.

In this study, we have introduced the dominant, superactive D443N mutation of SCAP into the livers of mice. The cleavage of endogenous SREBP-1 and SREBP-2 was increased in the transgenic livers, resulting in increased amounts of nSREBP-1 and -2. The mRNAs for SREBP target genes in the cholesterol and fatty acid biosynthetic pathways were markedly elevated. This resulted in mice with enlarged livers that were engorged with cholesterol and triglycerides. Despite the elevation of hepatic cholesterol, the transgenic mice continued to cleave SREBPs and transcribe the genes of lipid synthesis. The animals were also partially resistant to the suppression effects of a high cholesterol diet. These results indicate that SCAP plays a central role in the regulation of SREBP processing in mouse liver.

\section{Methods}

Materials and general methods. We obtained restriction and DNA modifying enzymes from New England Biolabs, Inc. (Beverly, MA); a cDNA probe for mouse glyceraldehyde-3-phosphate dehydrogenase (GAPDH) from Ambion, Inc. (Austin, TX); AmpliTaq Gold DNA polymerase from Perkin-Elmer Corp. (Branchburg, NJ); and Redivue $\left[\alpha{ }^{32} \mathrm{P}\right] \mathrm{dCTP}(3,000 \mathrm{Ci} / \mathrm{mmol}),\left[\alpha-{ }^{32} \mathrm{P}\right] \mathrm{CTP}(800 \mathrm{Ci} / \mathrm{mmol})$, and $\left[\alpha{ }^{-32} \mathrm{P}\right] \mathrm{UTP}(800 \mathrm{Ci} / \mathrm{mmol})$ from Amersham Corp. (Arlington Heights, IL). DNA sequencing was performed on a DNA sequencer (model 377A; Applied Biosystems, Foster City, CA) using the dideoxy chain termination method. The hepatic and plasma content of cholesterol and triglycerides was measured as previously described $(24,25)$.

Plasmid constructions. An expression plasmid encoding a mutant version of hamster SCAP containing an aspartic acid to asparagine substitution at codon 443 (D443N) under the control of the rat phosphoenolpyruvate carboxykinase (PEPCK) promoter was constructed in a trimolecular ligation reaction. The 2.4-kb BglII fragment of the rat PEPCK promoter (which contains sequence elements responsible for tissue-specific and dietary regulation; reference 26) was ligated into BgIII/SpeI-digested pTK-HSV-SCAP(D443N) (which encodes herpes simplex virus (HSV) epitope-tagged hamster SCAP(D443N) (16) and $\mathrm{BglII} / \mathrm{XbaI}$-digested $\mathrm{pRI}_{2}$-intronA (which contains the rat insulin II intron A known to enhance expression of transgenes in mice; reference 27). The structure of the resulting plasmid, designated pPEPCK-HSV-SCAP(D443N), was confirmed by restriction analysis and DNA sequencing of all ligation joints.

Transgenic mice. Techniques used for generating transgenic mice were previously described (28). The AatII-AvrII fragment of pPEPCK-HSV-SCAP(D443N) was purified on a SeaKem GTG agarose gel (FMC Bioproducts, Rockland, ME) and isolated by perchlorate elution (29). A total of 373 fertilized eggs that were microinjected with the DNA fragment survived to the two-cell stage and were transferred to pseudopregnant recipients. Among the 71 offspring, 21 had integrated the transgene as determined by dot blot hybridization of DNA from tail homogenates. Of the 21 founder mice subjected to partial hepatectomy, nine produced transgenic SCAP as determined by immunoblot analysis (16). Mice with high levels of transgene expression in liver were bred to $\mathrm{C} 57 \mathrm{BL} / 6 \mathrm{~J} \times \mathrm{SJL}$ F1 mice, and three lines of PEPCK-HSV-SCAP(D443N) mice were established. Each line had similar levels of hepatic expression of the transgene, and all three lines showed fatty livers of comparable size. One line, designated L969-4, was used for the experiments described in this study. Mice were housed in colony cages and maintained on a 14-h light/10-h dark cycle.

Diets. Three diets were used: (a) standard chow diet consisting of a 4\% (wt/wt) animal fat mouse/rat diet 7001 (Harland Teklad, Madison, WI), (b) standard chow diet mixed with $1 \%$ (wt/wt) cholesterol (ICN Pharmaceuticals, Inc., Costa Mesa, CA) and $0.5 \%$ (wt/wt) cholic acid (ICN Pharmaceuticals, Inc.), and (c) standard chow mixed with $0.5 \%$ cholesterol and $0.25 \%$ cholic acid.

Immunoblotting. Nuclear extracts and membrane fractions $\left(10^{5}-\mathrm{g}\right.$ pellet) were prepared from mouse livers immediately after exsanguination as described previously for hamster livers (30). Aliquots of membranes $(50-\mu \mathrm{g}$ protein) and nuclear extract (30- $\mu \mathrm{g}$ protein) were subjected to $8 \%$ SDS-PAGE, transferred to Hybond C Extra membranes (Amersham Corp.), and incubated with $5 \mu \mathrm{g} / \mathrm{ml}$ rabbit antimouse SREBP-1 IgG or $5 \mu \mathrm{g} / \mathrm{ml}$ rabbit anti-mouse SREBP-2 IgG (directed against amino acids 32-250 of SREBP-1 or SREBP-2, respectively; reference 31). Protein content of samples was determined with the BCA Kit (Pierce Chemical Co., Rockford, IL). Protein gels were calibrated with prestained molecular weight markers (Bio Rad, Hercules, CA). Immunoblot analysis was carried out with the Enhanced Chemiluminescence (ECL) Western Blotting Detection System $\mathrm{Kit}^{\mathrm{TM}}$ (Amersham Corp.) with a horseradish-peroxidase conjugated donkey anti-rabbit secondary antibody (Jackson Immunoresearch Laboratories, West Grove, PA).

RNase protection assay. cDNA fragments of transgenic hamster SCAP(D443N) and endogenous mouse SCAP were amplified by PCR of pTK-HSV-SCAP(D443N) and first-strand cDNA prepared from mouse poly $(\mathrm{A})^{+}$RNA, respectively, by using the following primers: hamster SCAP $5^{\prime}$ primer $5^{\prime}$-TGGATTGGCATCCTGG- 
TATACACAG-3', and 3' primer 5'-GCGACCATCCTGAGGTTGCCGC-3' (16); and mouse SCAP 5' primer 5'-GAGAACCTG-

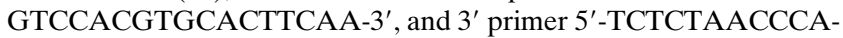
ATAACCACCAC-3' (16). HindIII and EcoRI sites were added to all $5^{\prime}$ and $3^{\prime}$ primers, respectively, and subcloned into pGEM-3Zf $(+)$ vector (Promega Corp., Madison, WI) as described (32). Probes for mouse SCD1 and SCD2 were previously reported (33). After linearization of the plasmid DNA with HindIII, antisense RNA was synthesized with either $\left[\alpha{ }^{32} \mathrm{P}\right] \mathrm{CTP}$ or $\left[\alpha{ }^{32} \mathrm{P}\right] \mathrm{UTP}$ by using bacteriophage T7 RNA polymerase (Ambion, Inc.). Specific activities of the cRNAs were measured in each experiment and were in the range of $1.7-2.6 \times 10^{9} \mathrm{cpm} / \mu \mathrm{g}$ except for $\beta$-actin which was $5.3-8.1 \times 10^{8} \mathrm{cpm} /$ $\mu \mathrm{g}$, as a result of dilution of the $\left[\alpha-{ }^{32} \mathrm{P}\right] \mathrm{CTP}$ or $\left[\alpha-{ }^{32} \mathrm{P}\right] \mathrm{UTP}$.

Aliquots of total RNA ( 5 or $15 \mu \mathrm{g}$ ) were assayed by RNase protection with a HybSpeed II RPA kit (Ambion, Inc.) as previously described $(32,33)$. Each assay tube contained the indicated cRNA probe for the mRNA to be tested plus cRNA complementary to the $\beta$-actin mRNA. After digestion with RNase, the protected fragments were separated on an $8 \mathrm{M}$ urea $/ 4.8 \%$ polyacrylamide gel. Dried gels were exposed to film (Reflection ${ }^{\mathrm{TM}} \mathrm{NEF} 4$ 496; New England NuclearDuPont, Boston, MA) and intensifying screens for $16 \mathrm{~h}$ at $-80^{\circ} \mathrm{C}$. Quantification of protected fragments for each test mRNA was carried out on a Bio-Imaging Analyzer (Fuji Medical Systems, Standish, $\mathrm{ME}$ ), and the values were normalized to the signal generated by the level of $\beta$-actin mRNA in the same RNA sample.

Blot hybridization of RNA. Total RNA was prepared from mouse liver using the RNeasy ${ }^{\mathrm{TM}}$ Total RNA kit (Qiagen Inc., Chatsworth, CA) or RNA Stat 60 (Tel Test "B" Inc., Friendswood, TX). Equal aliquots of total RNA from mice in each group were pooled (total, 15 $\mu \mathrm{g}$ ) and subjected to Northern blot analysis with the indicated cDNA probes prepared as previously described (31-35). The indicated cDNA probes were labeled by the random primer method using the Prime-It II Kit (Stratagene, La Jolla, CA) with $\left[\alpha-{ }^{32} \mathrm{P}\right] \mathrm{dCTP}$. The ${ }^{32} \mathrm{P}-$ labeled probe was purified on a G-50 spin column (Pharmacia Biotech, Piscataway, NJ), hybridized to the filters $\left(\sim 2 \times 10^{6} \mathrm{cpm} / \mathrm{ml}\right)$ using Rapid-hyb buffer (Amersham Corp.) for $2 \mathrm{~h}$ at $65^{\circ} \mathrm{C}$, washed twice with $0.1 \%$ (wt $/ \mathrm{vol}$ ) SDS $/ 0.1 \times \mathrm{SSC}$ at $65^{\circ} \mathrm{C}$ for $30 \mathrm{~min}$, and exposed to film (either X-OMAT; Kodak, Rochester, NY; or Reflection $^{\text {TM }}$ NEF 496; New England Nuclear-Dupont) with intensifying screens for $3-36 \mathrm{~h}$ at $-80^{\circ} \mathrm{C}$ or $0.15-3 \mathrm{~h}$ at room temperature. The resulting bands were quantified on a Bio-Imaging Analyzer (Fuji Medical Systems) as described above, and the results were normalized to the signal generated from hybridization of a ${ }^{32} \mathrm{P}$-labeled mouse GAPDH cDNA probe on the same filter.

Hepatic cholesterol and fatty acid synthesis in vivo. The rates of cholesterol and fatty acid synthesis were measured in littermate 12-

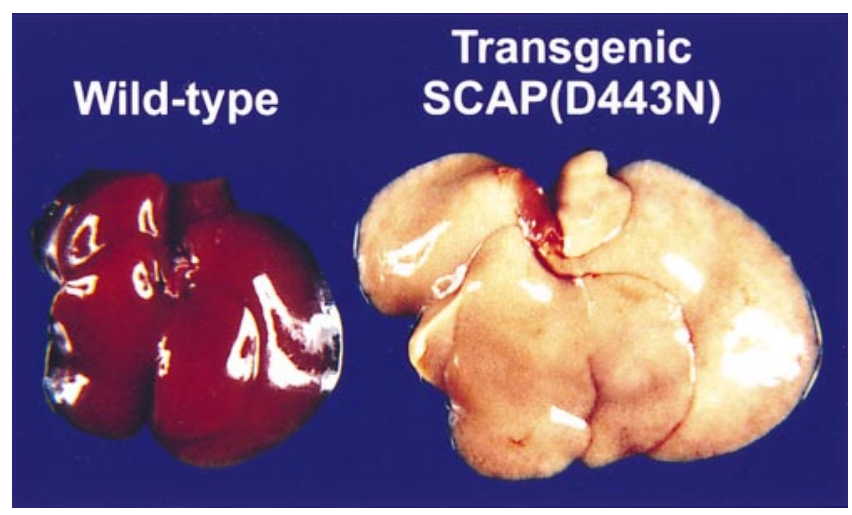

Figure 1. Livers from 12-wk-old wild-type (left) and TgSCAP(D443N) (right) male mice from the same litter. Animals were maintained on the standard chow diet.

wk-old mice during the early light cycle after a 3-h fast. Each animal was injected intraperiotoneally with $50 \mathrm{mCi}$ of $\left[{ }^{3} \mathrm{H}\right]$ water in $0.1 \mathrm{ml}$ isotonic saline. $1 \mathrm{~h}$ after injection, mice were anesthetized and 300$500 \mu \mathrm{l}$ of blood was removed to determine the specific activity of plasma $\left[{ }^{3} \mathrm{H}\right]$ water in duplicate. The amounts of digitonin-precipitable $\left[{ }^{3} \mathrm{H}\right]$ sterols and $\left[{ }^{3} \mathrm{H}\right]$ fatty acids were measured after saponification of 200-300 mg aliquots of liver as previously described (34). The results are expressed as $\mu \mathrm{mol}$ of $\left[{ }^{3} \mathrm{H}\right]$ water incorporated into digitonin-precipitable sterols or fatty acids per hour per gram of tissue.

SCD activity. SCD activity was measured in microsomes of mouse liver as previously described (33). Each assay contained $0.1 \mathrm{M}$ potassium phosphate ( $\mathrm{pH} 7.2), 2 \mathrm{mM}$ NADH, $60 \mu \mathrm{M}\left[1-{ }^{14} \mathrm{C}\right]$ stearoyl $\mathrm{CoA}(23 \mathrm{dpm} / \mathrm{pmol})$, and $0.1 \mathrm{mg}$ of microsomal protein in a final volume of $0.1 \mathrm{ml}$. After incubation for $5 \mathrm{~min}$ at $37^{\circ} \mathrm{C}$, the reaction mixture was saponified, and the fatty acids were methylated and separated by argentation thin layer chromatography (36). The band migrating with the oleic acid standard was subjected to liquid scintillation counting. Enzyme activity is expressed as the pmol of $\left[{ }^{14} \mathrm{C}\right]$ stearoyl CoA converted to $\left[{ }^{14} \mathrm{C}\right]$ oleic acid per minute per milligram of microsomal protein.

Fatty acid composition of liver extracts. Total lipids were extracted from 300-350 mg aliquots of mouse liver and then separated on 500-mg silica columns (catalog No. 1211-3036; Varian, Harbor City, CA) as described (37). After saponification, the fatty acids in each sample were methylated and the relative abundance of each fatty acid was quantified by gas-liquid chromatography (GLC) $(38,39)$.

Table I. Phenotypic Comparison between Male Wild-type and TgSCAP(D443N) Transgenic Mice

\begin{tabular}{|c|c|c|c|c|}
\hline \multirow[b]{2}{*}{ Parameter } & \multicolumn{2}{|c|}{ Experiment A: 7-9 wk of age } & \multicolumn{2}{|c|}{ Experiment B: $15-17 \mathrm{wk}$ of age } \\
\hline & Wild type & $\operatorname{TgSCAP}(\mathrm{D} 443 \mathrm{~N})$ & Wild type & $\operatorname{TgSCAP}(\mathrm{D} 443 \mathrm{~N})$ \\
\hline Number & 3 & 4 & 4 & 4 \\
\hline Body weight (g) & $23.7 \pm 1.3$ & $26.3 \pm 0.5$ & $26.4 \pm 0.7$ & $24.5 \pm 0.8$ \\
\hline Liver weight $(\mathrm{g})$ & $1.4 \pm 0.1$ & $2.2 \pm 0.2^{*}$ & $1.3 \pm 0.1$ & $2.1 \pm 0.1 *$ \\
\hline Epididymal fat pad weight (g) & $0.36 \pm 0.09$ & $0.33 \pm 0.03$ & $0.32 \pm 0.03$ & $0.29 \pm 0.03$ \\
\hline Liver cholesterol content $(\mathrm{mg} / \mathrm{g})$ & $2.2 \pm 0.1$ & $12.4 \pm 1.2^{\ddagger}$ & $2.3 \pm 0.1$ & $13.5 \pm 1.4^{\ddagger}$ \\
\hline Liver triglyceride content $(\mathrm{mg} / \mathrm{g})$ & $7.1 \pm 0.4$ & $66.1 \pm 6.4^{\ddagger}$ & $10.2 \pm 1.4$ & $94.6 \pm 12.2^{\ddagger}$ \\
\hline Total plasma cholesterol (mg/dl) & $103 \pm 8.3$ & $50 \pm 2.8^{\ddagger}$ & $100 \pm 8.9$ & $50 \pm 7.6^{\ddagger}$ \\
\hline Total plasma triglycerides $(\mathrm{mg} / \mathrm{dl})$ & $122 \pm 5.2$ & $61 \pm 2.2^{\ddagger}$ & $142 \pm 25.3$ & $76 \pm 13.0^{*}$ \\
\hline
\end{tabular}

Each value represents the mean \pm SEM of the indicated number of 7-9-wk-old mice or 15-17-wk-old mice. In each experiment, the wild-type mice consisted of nontransgenic littermates of the transgenic mice. All mice were maintained on the standard chow diet and were fasted for $3 \mathrm{~h}$ before killing. ${ }^{*} P<0.01$ : level of statistical significance (Student's $t$ test) between the indicated wild-type and transgenic mice. ${ }^{\ddagger} P<0.001$ : level of statistical significance (Student's $t$ test) between the indicated wild-type and transgenic mice. 


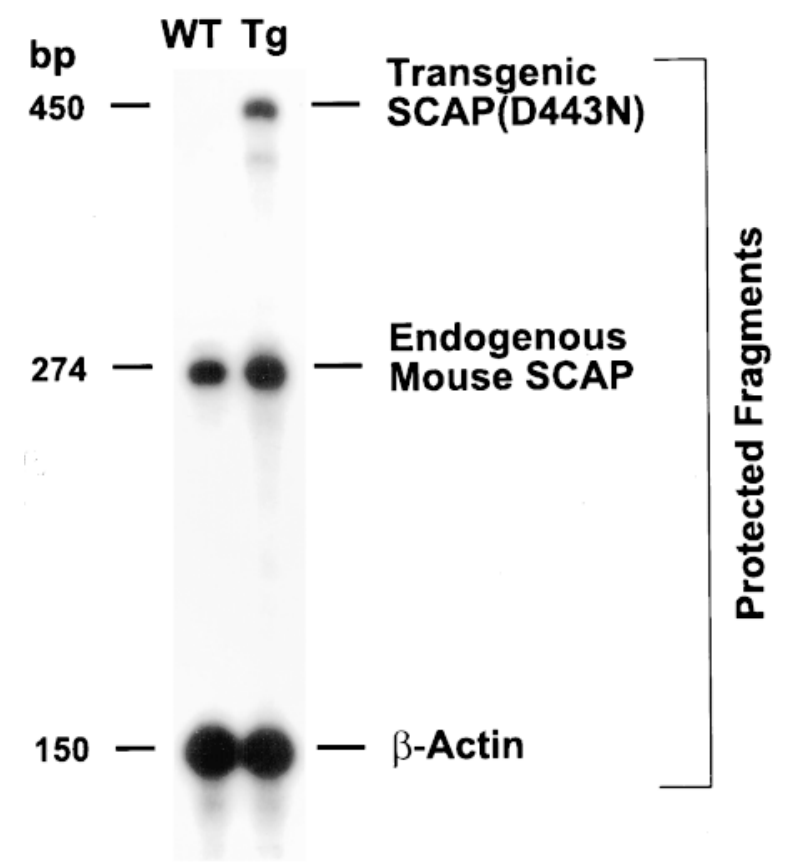

Figure 2. RNase protection assays of endogenous mouse SCAP mRNA and transgenic hamster SCAP(D443N) mRNA in livers from wild-type and TgSCAP(D443N) mice. Aliquots of total RNA $(15 \mu \mathrm{g})$ from the pooled livers of the mice described in Table I (experiment A) were hybridized in solution for $10 \mathrm{~min}$ at $68^{\circ} \mathrm{C}$ to the ${ }^{32} \mathrm{P}$-labeled cRNA probes for endogenous mouse SCAP, transgenic hamster SCAP(D443N), and $\beta$-actin as described in Methods. After RNase digestion, the protected fragments were separated by gel electrophoresis, and exposed to film (Reflection ${ }^{\mathrm{TM}} \mathrm{NEF} 496$; New England Nuclear-Dupont) with an intensifying screen for $16 \mathrm{~h}$ at $-80^{\circ} \mathrm{C}$.

\section{Results}

We constructed a transgene encoding SCAP(D443N) (16) under control of the PEPCK promoter (34). The encoded protein includes an $\mathrm{NH}_{2}$-terminal epitope tag derived from the HSV glycoprotein followed by the full-length D443N mutant version of hamster SCAP. To maintain a relatively physiologic level of expression of SCAP(D443N), the transgenic mice were fed a normal chow diet and not the low carbohydrate/ high protein diet that superactivates the PEPCK promoter.

Transgenic mice expressing SCAP(D443N) appeared normal at birth. The animals showed a normal pattern of growth except for the abdomen which became progressively distended, owing to an enlarged liver. Fig. 1 shows the livers of 12-wk-old wild-type and transgenic mice expressing SCAP(D443N). The liver from the transgenic mouse is enlarged and pale in color, owing to massive accumulation of lipids.

Table I compares quantitative parameters between 7-9-wkold wild-type and transgenic (Tg)SCAP(D443N) mice (experiment A) and between 15-17-wk-old wild-type and TgSCAP(D443N) mice (experiment B). The body weights did not vary between wild-type and transgenic littermates, but the liver weights were increased 1.6-fold in the transgenic mice. The hepatic content of cholesterol and triglyceride was elevated by sixfold and ninefold, respectively. The plasma of the transgenic mice showed a $50 \%$ reduction in both cholesterol and triglycerides.

To quantify the expression level of the SCAP(D443N) transgene, an RNase protection assay was established to distinguish between endogenous mouse SCAP and transgenic hamster SCAP(D443N). Total RNA from wild-type and transgenic livers was hybridized with ${ }^{32} \mathrm{P}$-labeled cRNA probes for mouse SCAP, TgSCAP(D443N), and an internal standard, $\beta$-actin (Fig. 2). The cRNA probe for endogenous mouse SCAP yielded a protected band of $274 \mathrm{bp}$ in wild-type and transgenic livers. A protected fragment of $450 \mathrm{bp}$ that corresponds to the mRNA for hamster SCAP(D443N) was present in the transgenic animals and absent in wild-type littermates. Quantitative analysis of these data revealed that the ratio of SCAP(D443N) mRNA to endogenous mouse SCAP mRNA was 0.3 in the transgenic animals.

To determine the effect of the SCAP(D443N) transgene on cleavage of endogenous SREBPs, nuclear SREBP (nSREBP) protein was measured by immunoblotting in extracts of livers from the wild-type and transgenic mice that were described in experiments A and B of Table I. The transgenic livers showed a substantial increase in the amount of nSREBP-1 and a concomitant decrease in the amount of the membrane-bound precursor (Fig. 3, lanes 1, 2, 5, and 6). Similar changes were observed for SREBP-2 (lanes 3, 4, 7, and 8).

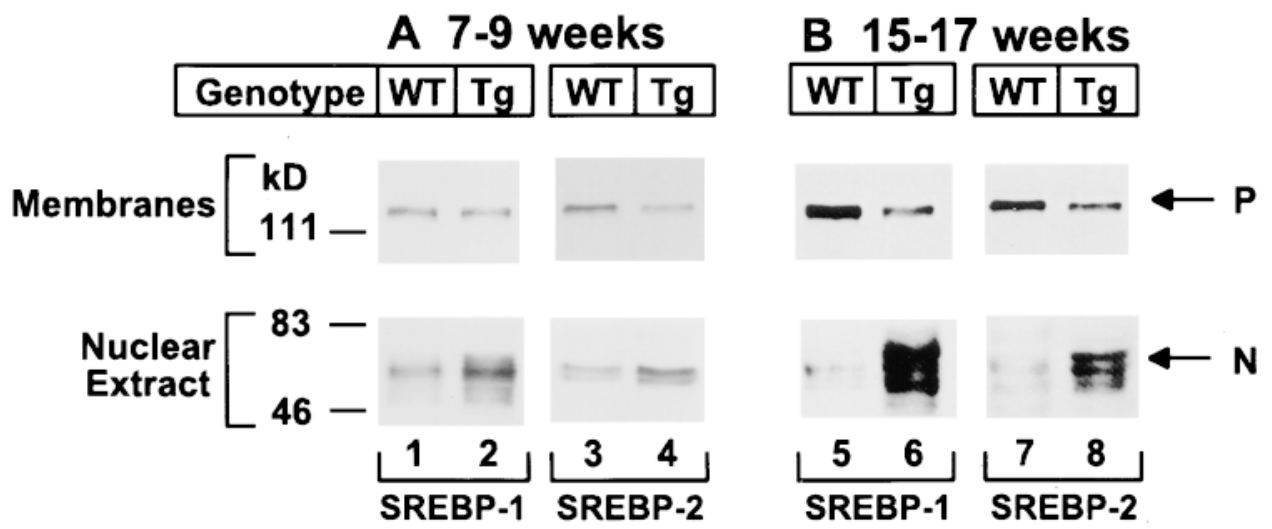

Figure 3. Immunoblot analysis of SREBP-1 and SREBP-2 in membranes and nuclear extracts from livers of wild-type and SCAP(D443N) transgenic mice at different ages. Livers from the two groups of mice in Table I (experiments A and B) were separately pooled, and aliquots of the membrane pellet $(50 \mu \mathrm{g}$ protein) and nuclear extract $(30 \mu \mathrm{g})$ were subjected to $8 \%$ SDS-PAGE. Immunoblot analysis was performed using $5 \mu \mathrm{g} / \mathrm{ml}$ of rabbit anti-mouse SREBP-1 IgG (lanes 1,2, 5, and 6) or SREBP-2 IgG (lanes 3, 4, 7, and 8 ) as the primary antibody and 0.25 $\mu \mathrm{g} / \mathrm{ml}$ horseradish peroxidase-coupled donkey anti-rabbit IgG as the secondary antibody. Filters were exposed to film (Reflection ${ }^{\mathrm{TM}} \mathrm{NEF} 496$; New England Nuclear-Dupont) for $15 \mathrm{~s}$ (lanes 1 and 2), $30 \mathrm{~s}$ (lanes 3-6), and $45 \mathrm{~s}$ (lanes 7 and 8 ) at room temperature. $P$ and $N$ denote the precursor and cleaved nuclear forms of SREBP, respectively. 


\begin{tabular}{|c|c|c|c|c|c|c|}
\hline $\begin{array}{c}\text { SREBP } \\
\text { Probe }\end{array}$ & \multicolumn{2}{|c|}{ 1a } & \multicolumn{2}{|c|}{ 1c } & \multicolumn{2}{c|}{2} \\
\hline Genotype & WT & Tg & WT & Tg & WT & Tg \\
\hline Lane & A & B & C & D & E & F \\
\hline
\end{tabular}

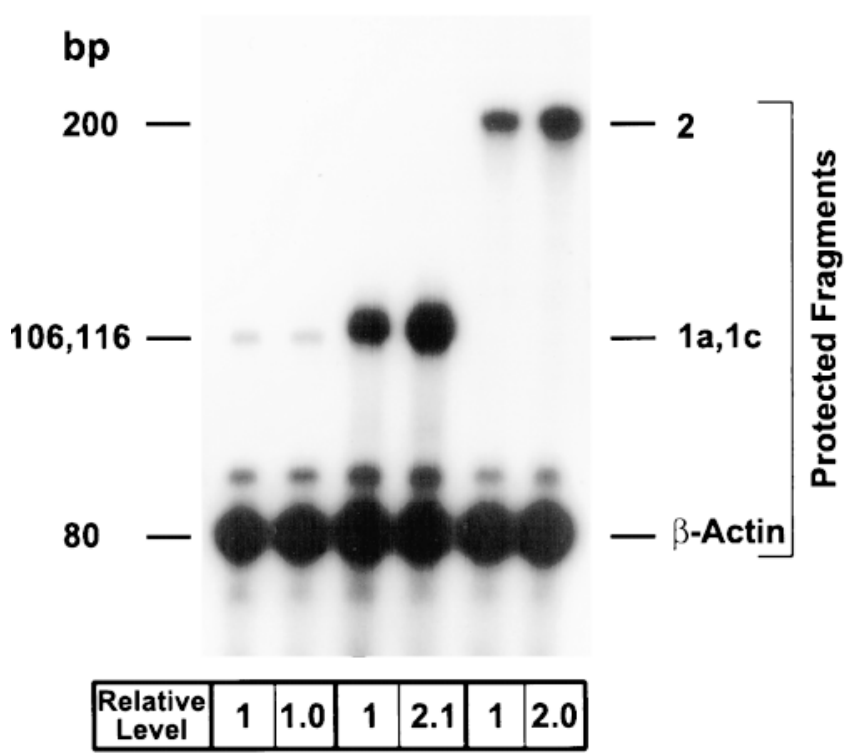

Figure 4. Amounts of mRNA for SREBP-1a, -1c, and -2 in livers of wild-type mice (lanes $A, C$, and $E$ ) and TgSCAP(D443N) mice (lanes $B, D$, and $F$ ). Total RNA from mice in Table I (experiment A) was isolated from pooled livers as described in Methods. Aliquots of total RNA $(15 \mu \mathrm{g})$ from the indicated source were hybridized in solution for $10 \mathrm{~min}$ at $68^{\circ} \mathrm{C}$ to the indicated ${ }^{32} \mathrm{P}$-labeled cRNA probes for SREBP-1a, SREBP-1c, or SREBP-2, all in the presence of a ${ }^{32} \mathrm{P}-$ labeled cRNA probe for $\beta$-actin as described in Methods. After RNase digestion, the protected fragments were separated by gel electrophoresis, exposed to film (Reflection ${ }^{\mathrm{TM}} \mathrm{NEF}$ 496; New England Nuclear-Dupont) with an intensifying screen for $16 \mathrm{~h}$ at $-80^{\circ} \mathrm{C}$, and quantified by a Bio-Imaging Analyzer (Fuji Medical Systems). The sizes of the protected fragments for SREBP-1a and SREBP-1c are 106 and $116 \mathrm{bp}$, respectively. The quantitative data were corrected for the number of ${ }^{32} \mathrm{P}$-atoms in each protected fragment (32).

The SREBP-1 gene gives rise to two transcripts, designated $-1 \mathrm{a}$ and $-1 \mathrm{c}$, that differ in the length of the $\mathrm{NH}_{2}$-terminal acidic domain that serves as a transcription activator $(32,35)$. SREBP-1a has a longer acidic activation domain, and there- fore it is a much more potent transcriptional activator than SREBP-1c. The SREBP-1 antibody used for the immunoblots of Fig. 3 does not distinguish between SREBP-1a and -1c. We therefore refer to these isoforms generically as SREBP-1. To measure the amounts of the mRNAs for SREBP-1a and -1c separately, we used a sensitive RNase protection assay (32). In wild-type livers, the amount of the mRNA for SREBP-1a was low, and it was unaffected by the transgene (Fig. 4, lanes $A$ and $B)$. The amounts of SREBP-1c and SREBP-2 mRNAs were relatively high, and they were both increased approximately twofold in the transgenic mice (lanes $C-F$ ).

Fig. 5 shows the amounts of multiple mRNAs encoding proteins involved in lipid metabolism in wild-type and transgenic livers as estimated by Northern blot analysis. Significant increases were measured in the mRNAs for SREBP-1, SREBP-2, and the LDL receptor as well as multiple enzymes involved in cholesterol biosynthesis. In particular, there was a pronounced 18-fold increase in the mRNA for HMG CoA reductase, a rate-controlling enzyme in the cholesterol biosynthetic pathway. The mRNAs for the fatty acid biosynthetic enzymes acetyl CoA carboxylase, fatty acid synthase, and SCD were also significantly increased. Increases were also observed for the mRNAs encoding malic enzyme and ATP citrate lyase, which supply NADPH and acetyl CoA for fatty acid synthesis, respectively. The mRNA for glycerol-3-phosphate acyltransferase (GPAT) was also increased. This enzyme carries out a crucial step in phospholipid and triglyceride synthesis (13). We found no changes in the mRNAs for three apoproteins of the lipoprotein transport system, namely apo AI, apo B, and apo E. The mRNA analyses in Fig. 5 were repeated in three independent experiments involving different litters of mice, and similar quantitative results were obtained.

To confirm that the elevated mRNAs for the cholesterol and fatty acid biosynthetic enzymes in the transgenic livers led to increased rates of lipid synthesis, we measured the in vivo rates of synthesis of cholesterol and fatty acids using intraperitoneally injected $\left[{ }^{3} \mathrm{H}\right]$ water (34). Table II shows that transgenic livers had five- and sevenfold increases in the rates of incorporation of $\left[{ }^{3} \mathrm{H}\right]$ water into digitonin-precipitable sterols and fatty acids, respectively, when expressed per gram of liver. Inasmuch as the transgenic livers were significantly larger than wild-type livers, the total increase in synthesis per organ was even greater.

In previous experiments, we showed that overexpression of SREBP-1a or SREBP-2 stimulates transcription of the gene encoding SCD2, an isoform of SCD whose mRNA is not nor-

Table II. In Vivo Synthesis of Sterols and Fatty Acids in Livers from Wild-type and TgSCAP(D443N) Mice

\begin{tabular}{|c|c|c|c|c|c|}
\hline \multirow{3}{*}{ Genotype of mice } & \multirow{3}{*}{$\frac{\text { Liver weight }}{g}$} & \multicolumn{4}{|c|}{ Incorporation of $\left[{ }^{3} \mathrm{H}\right]$ water into } \\
\hline & & \multicolumn{2}{|c|}{ Digitonin-precipitable sterols } & \multicolumn{2}{|c|}{ Fatty acids } \\
\hline & & $\mu m o l / h / g$ & umol/h/organ & $\mu m o l / h / g$ & $\mu \mathrm{mol} / \mathrm{h} / \mathrm{organ}$ \\
\hline Wild type & $1.1 \pm 0.1$ & $0.91 \pm 0.1$ & $1.0 \pm 0.2$ & $5.9 \pm 1.1$ & $6.2 \pm 1.4$ \\
\hline $\operatorname{TgSCAP}(\mathrm{D} 443 \mathrm{~N})$ & $2.4 \pm 0.2 *$ & $4.7 \pm 1.3^{\ddagger}$ & $10.4 \pm 2.4^{\ddagger}$ & $43.8 \pm 3.8^{*}$ & $106.1 \pm 17.3 *$ \\
\hline
\end{tabular}

Each value represents the mean \pm SEM of four 12 -wk-old littermate mice of the indicated genotype. All mice were maintained on the standard chow diet and fasted for $3 \mathrm{~h}$ before intraperitoneal injection of $\left[{ }^{3} \mathrm{H}\right]$ water. $1 \mathrm{~h}$ after injection, the liver was removed for measurement of its content of ${ }^{3} \mathrm{H}$ labeled digitonin-precipitable sterols and fatty acids as described in Methods. ${ }^{*} P<0.01$ : level of statistical significance (Student's $t$ test) between the indicated line of wild-type and transgenic mice. ${ }^{\ddagger} P<0.05$ : level of statistical significance (Student’s $t$ test) between the indicated line of wild-type and transgenic mice. 


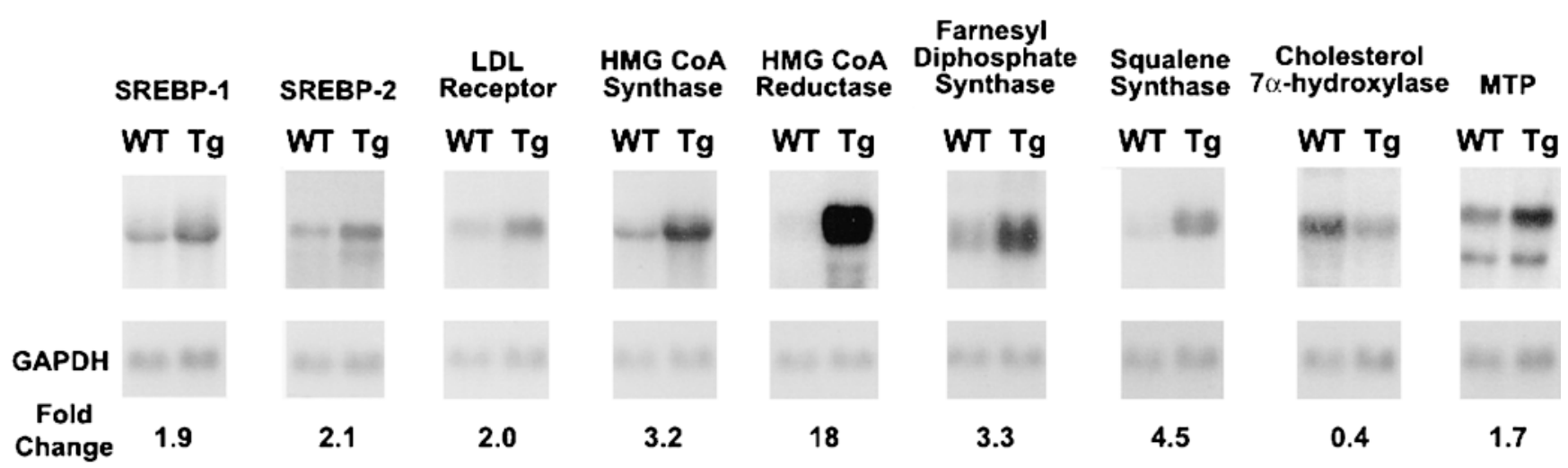

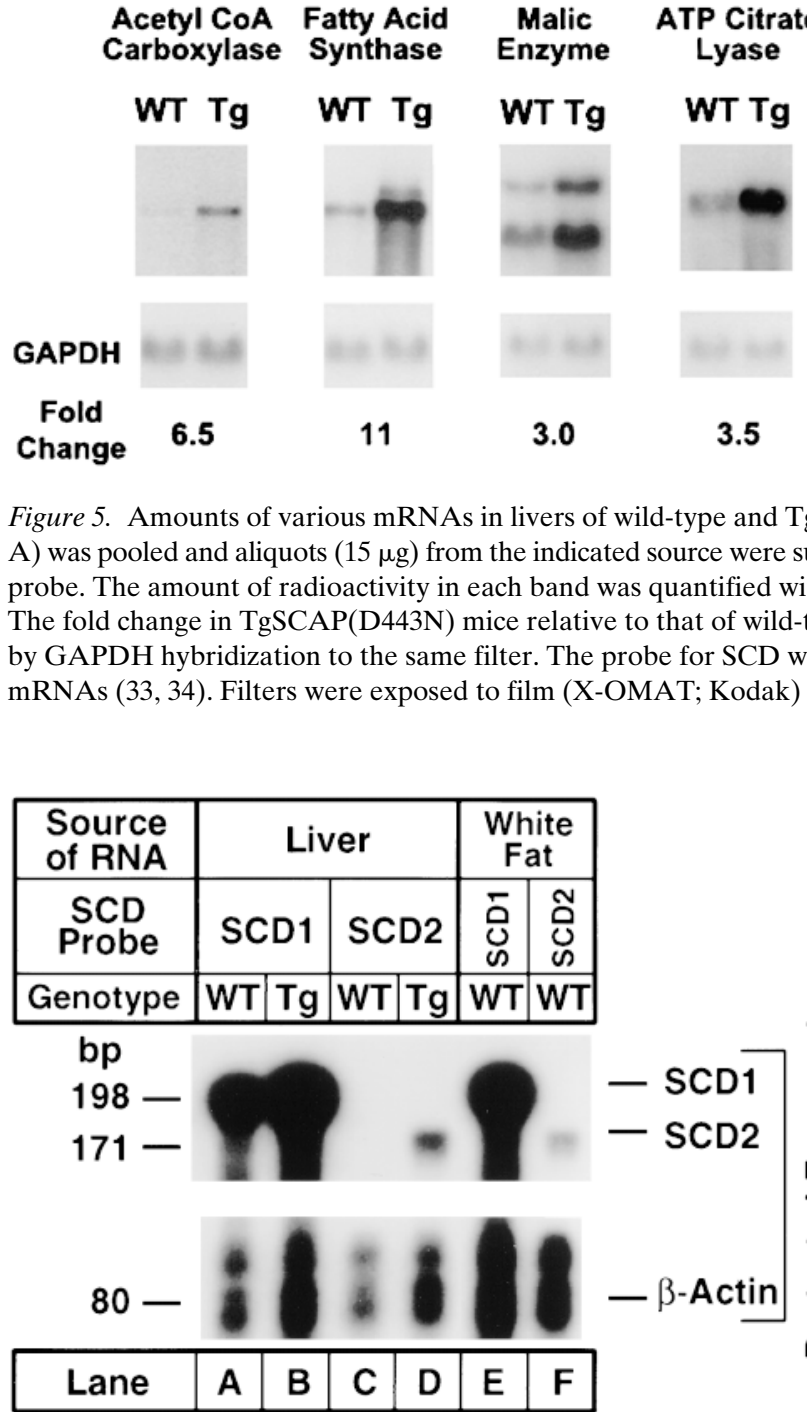

Figure 6. Amounts of mRNA for SCD-1 and SCD-2 in livers of wildtype and TgSCAP(D443N) mice. Total RNA from mice in Table I (experiment A) was isolated from pooled livers. Aliquots of total RNA $(5 \mu \mathrm{g})$ from the indicated source were hybridized in solution for $10 \mathrm{~min}$ at $68^{\circ} \mathrm{C}$ to the indicated ${ }^{32} \mathrm{P}$-labeled cRNA probes for SCD-1 or SCD-2 in the presence of a ${ }^{32} \mathrm{P}$-labeled cRNA probe for $\beta$-actin as described in Methods. After RNase digestion, the protected fragments were separated by gel electrophoresis and exposed to film (Reflection $^{\mathrm{TM}}$ NEF 496; New England Nuclear-Dupont) with an intensifying screen for $16 \mathrm{~h}$ at $-80^{\circ} \mathrm{C}$. mally detected in liver (33). Tabor et al. (14) recently showed in promoter-reporter assays that transfected rat SREBP-1c/ ADD1 activates transcription of the SCD2 gene in cultured human HepG2 cells. In Fig. 5, the cDNA probe for SCD could potentially cross-react with both SCD1 and SCD2. To distinguish between the two isoforms, we again used an RNase protection assay (Fig. 6). As a positive control, we studied mRNA from epididymal fat pads of wild-type mice, which are known

Table III. SCD Activity in Livers from Wild-type and $\operatorname{TgSCAP}(D 443 N)$ Mice

\begin{tabular}{lcc}
\hline Genotype of mice & Liver weight & SCD activity \\
\hline & $g$ & pmol/min per $m g$ \\
Wild type & $1.4 \pm 0.1$ & $326 \pm 152$ \\
TgSCAP(D443N) & $2.0 \pm 0.1^{*}$ & $1032 \pm 184^{\ddagger}$
\end{tabular}

Each value represents the mean \pm SEM of four 16 -wk-old male littermate mice of the indicated genotype. All mice were maintained on the standard chow diet and fasted for $3 \mathrm{~h}$ before killing. Microsomes were prepared from individual livers and incubated with $\left[{ }^{14} \mathrm{C}\right]$ stearoyl $\mathrm{CoA}$ as described in Methods. ${ }^{*} P<0.01$ : level of statistical significance (Student's $t$ test) between the indicated line of wild-type and transgenic mice. ${ }^{\ddagger} P<0.005$; Level of statistical significance (Student's $t$ test) between the indicated line of wild-type and transgenic mice. 


\section{Hepatic Fatty Acid Composition}

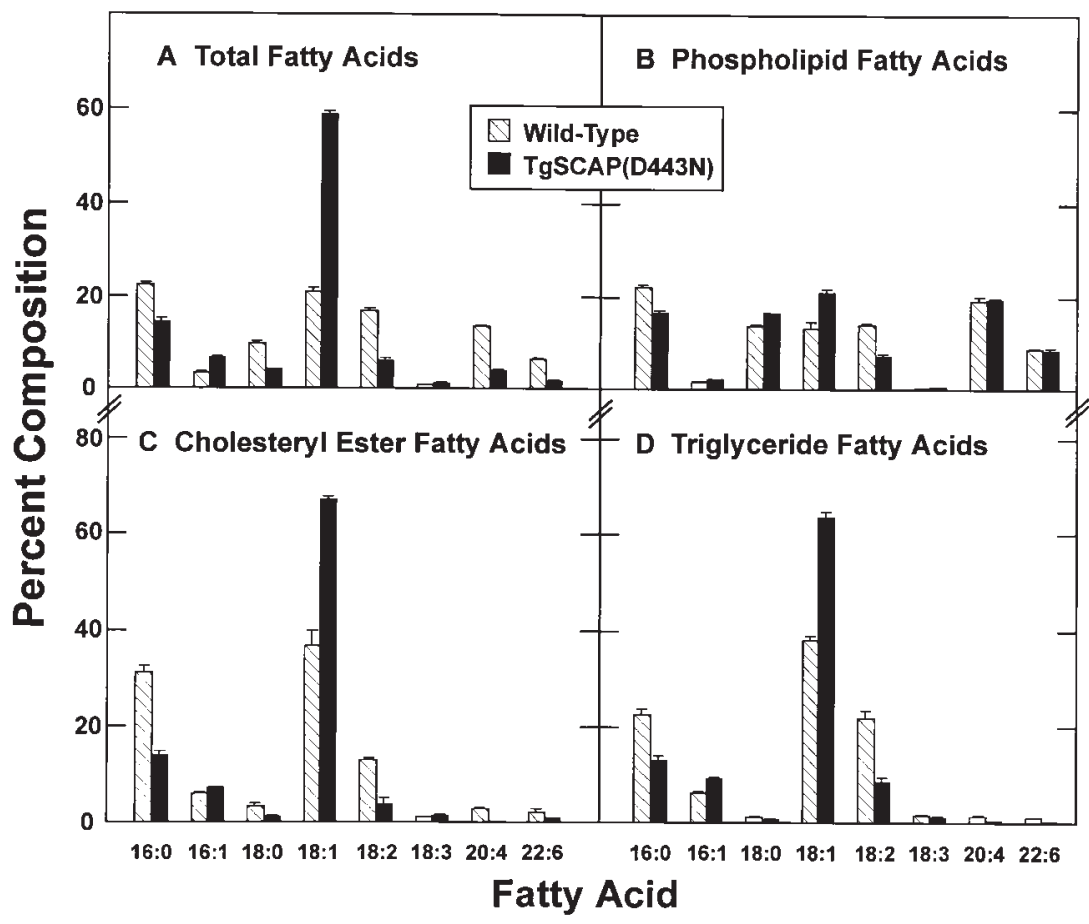

Figure 7. Relative fatty acid composition of lipids from livers of wild-type and $\operatorname{TgSCAP}(\mathrm{D} 443 \mathrm{~N})$ mice on the standard chow diet. Four male mice (12 wk old) in each group were killed, the liver lipids were separated, and the fatty acid content was measured by GLC as described in Methods. Each value represents the mean \pm SEM of values from four male mice. Values are expressed as the percent of the total fatty acids in each lipid class. Error bars denote SEM. The mean \pm SEM values for liver weights for the wild-type and transgenic mice were $1.4 \pm 0.1$ and $2.0 \pm 0.2 \mathrm{~g}$, respectively. to express both SCD isoforms (Fig. 6, lanes $E$ and $F$ ) $(40,41)$. In the transgenic livers, the mRNA for SCD1 was increased by twofold (Fig. 6, lanes $A$ and $B$ ). In wild-type mice, the mRNA for SCD2 was absent, but it appeared in the transgenic livers (Fig. 6, lanes $C$ and $D$ ), reaching the same level as observed in white adipose tissue.

To confirm that the increases in SCD1 and SCD2 mRNA in the transgenic mice resulted in increased desaturase activity, we measured SCD activity in extracts from livers of wild-type and transgenic littermates. Table III shows the mean SCD activities from liver microsomes as determined by the rate of conversion of $\left[1-{ }^{14} \mathrm{C}\right]$ stearoyl $\mathrm{CoA}$ to $\left[1-{ }^{14} \mathrm{C}\right]$ oleate. The microsomes from the transgenic mice had threefold higher SCD enzyme activity compared to littermate controls.
The primary products of fatty acid synthesis are the two saturated fatty acids, palmitic acid (16 carbons/0 double bonds) and stearic acid (18:0). SCD converts these to the monounsaturated fatty acids palmitoleic acid (16:1) and oleic acid (18:1), respectively. To determine whether the increase in SCD activity led to an increase in the content of monounsaturated fatty acids in liver, we used a GLC assay to measure the total fatty acid composition and the composition of three classes of lipids in wild-type and transgenic livers (Fig. 7). The total amounts of monounsaturated fatty acids were elevated in the transgenic livers. There was a twofold increase in the relative amount of palmitoleic acid and a 2.8 -fold increase in oleic acid (Fig. 7, $A$ ). There was a concomitant reduction in the relative amounts of saturated and polyunsaturated fatty acids. The

Table IV. Content of Cholesterol in Plasma and Livers of Wild-type and TgSCAP(D443N) Mice on Different Diets

\begin{tabular}{|c|c|c|c|c|c|}
\hline \multirow[b]{2}{*}{ Diet } & \multirow[b]{2}{*}{ Duration of treatment } & \multicolumn{2}{|c|}{ Plasma cholesterol content } & \multicolumn{2}{|c|}{ Liver cholesterol content } \\
\hline & & Wild type & Transgenic & Wild type & Transgenic \\
\hline & $d$ & \multicolumn{2}{|c|}{$m g / d l$} & \multicolumn{2}{|c|}{$\mathrm{mg} / \mathrm{g}$ tissue } \\
\hline \multicolumn{6}{|l|}{ Experiment A } \\
\hline Chow & - & $98 \pm 8$ & $49 \pm 7 *$ & $2.1 \pm 0.3$ & $13 \pm 1.5^{*}$ \\
\hline $1 \%$ cholesterol $+0.5 \%$ cholic acid & 2 & $153 \pm 11$ & $100 \pm 18$ & $8.4 \pm 1.1$ & $13 \pm 2.7$ \\
\hline $1 \%$ cholesterol $+0.5 \%$ cholic acid & 4 & $157 \pm 42$ & $116 \pm 21$ & $14 \pm 3.6$ & $16 \pm 2.2$ \\
\hline \multicolumn{6}{|l|}{ Experiment B } \\
\hline Chow & - & $100 \pm 9$ & $50 \pm 8^{*}$ & $2.3 \pm 0.1$ & $15 \pm 1.4^{*}$ \\
\hline $0.5 \%$ cholesterol $+0.25 \%$ cholic acid & 14 & $130 \pm 15$ & $95 \pm 21$ & $9.4 \pm 2.0$ & $28 \pm 3.2^{\ddagger}$ \\
\hline
\end{tabular}

12-wk-old littermate male mice (same animals as in Figs. 8 and 9) were fed for the indicated time either chow diet or chow diet supplemented with either $1 \%$ cholesterol $/ 0.5 \%$ cholic acid (experiment A) or $0.5 \%$ cholesterol $/ 0.25 \%$ cholic acid (experiment B). The mice were fasted for $3 \mathrm{~h}$ before killing. Each value represents the mean \pm SEM of four mice. ${ }^{*} P<0.001$ : level of statistical significance (Student's $t$ test) between the indicated line of wildtype and transgenic mice. ${ }^{\ddagger} P<0.005$ : level of statistical significance (Student’s $t$ test) between the indicated line of wild-type and transgenic mice. 
increase in monounsaturated fatty acids was similarly reflected in the composition of the phospholipid, cholesteryl ester, and triglyceride fractions (Fig. 7, $B-D$ ).

The livers of the transgenic mice had increased levels of nSREBP-1 and - 2 despite a marked increase of hepatic cholesterol, which should have inhibited SREBP processing. This suggests that SCAP(D443N) may block feedback inhibition of SREBP processing in liver, as it does in cultured cells $(2,16)$. To test this hypothesis more directly, we fed the mice cholesterol plus a bile acid (cholic acid) in an attempt to increase the hepatic cholesterol content of wild-type mice to the levels observed in the SCAP(D443N) transgenics. The cholic acid was included to increase cholesterol absorption from the intestine and to downregulate hepatic cholesterol $7 \alpha$-hydroxylase, which initiates the conversion of cholesterol to bile acids, thereby lessening the cholesterol buildup (42). Table IV shows the hepatic and plasma cholesterol content of wild-type and transgenic animals when fed a $1 \%$ cholesterol $/ 0.5 \%$ cholic acid diet for 2 or $4 \mathrm{~d}$. After $4 \mathrm{~d}$ on the cholesterol/cholic acid diet, the liver cholesterol content of wild-type mice had risen to the level seen in the transgenic mice on a chow diet.

Fig. $8 \mathrm{~A}$ shows immunoblot analyses of SREBPs in nuclear extracts and membrane fractions from livers of the mice described in Table IV. In wild-type mice, supplementing the chow diet with $1 \%$ cholesterol $/ 0.5 \%$ cholic acid diet for 2 or $4 \mathrm{~d}$ resulted in a partial decrease of nSREBP-1 (Fig. $8 \mathrm{~A}$, lanes 1-3) and a complete disappearance of nSREBP-2 (Fig. $8 A$, lanes 7-9). In the transgenic mice on a chow diet, the content of nSREBP-1 and nSREBP-2 was markedly elevated (Fig. $8 A$, lanes 4 and 10 ). In these mice the $1 \%$ cholesterol $/ 0.5 \%$ cholic acid diet did not reduce the content of nSREBP-1 (Fig. $8 \mathrm{~A}$, lanes 5 and 6 ), but it did cause a detectable decrease in nSREBP-2 (Fig. $8 A$, lanes 11 and 12). Densitometric analysis of these blots showed that nSREBP-2 decreased by $>98 \%$ in the wild-type mice after 2 or $4 \mathrm{~d}$ on the cholesterol/cholic acid diet. In the transgenic mice, the level declined by $30 \%$ at $2 \mathrm{~d}$ and $80 \%$ at $4 \mathrm{~d}$.

To determine the effects of a more chronic ingestion of cholesterol, wild-type and transgenic animals were fed a $0.5 \%$ cholesterol $/ 0.25 \%$ cholic acid diet for $14 \mathrm{~d}$ (Fig. 8 B). Again, wild-type livers showed reduced nSREBP-1 (Fig. $8 \mathrm{~B}$, lane 2) and a complete absence of immunodetectable nSREBP-2 (Fig. $8 \mathrm{~B}$, lane 6$)$. In the transgenic livers, we observed no reduction in nSREBP-1 (Fig. $8 \mathrm{~B}$, lane 4 ) and only a partial reduction in
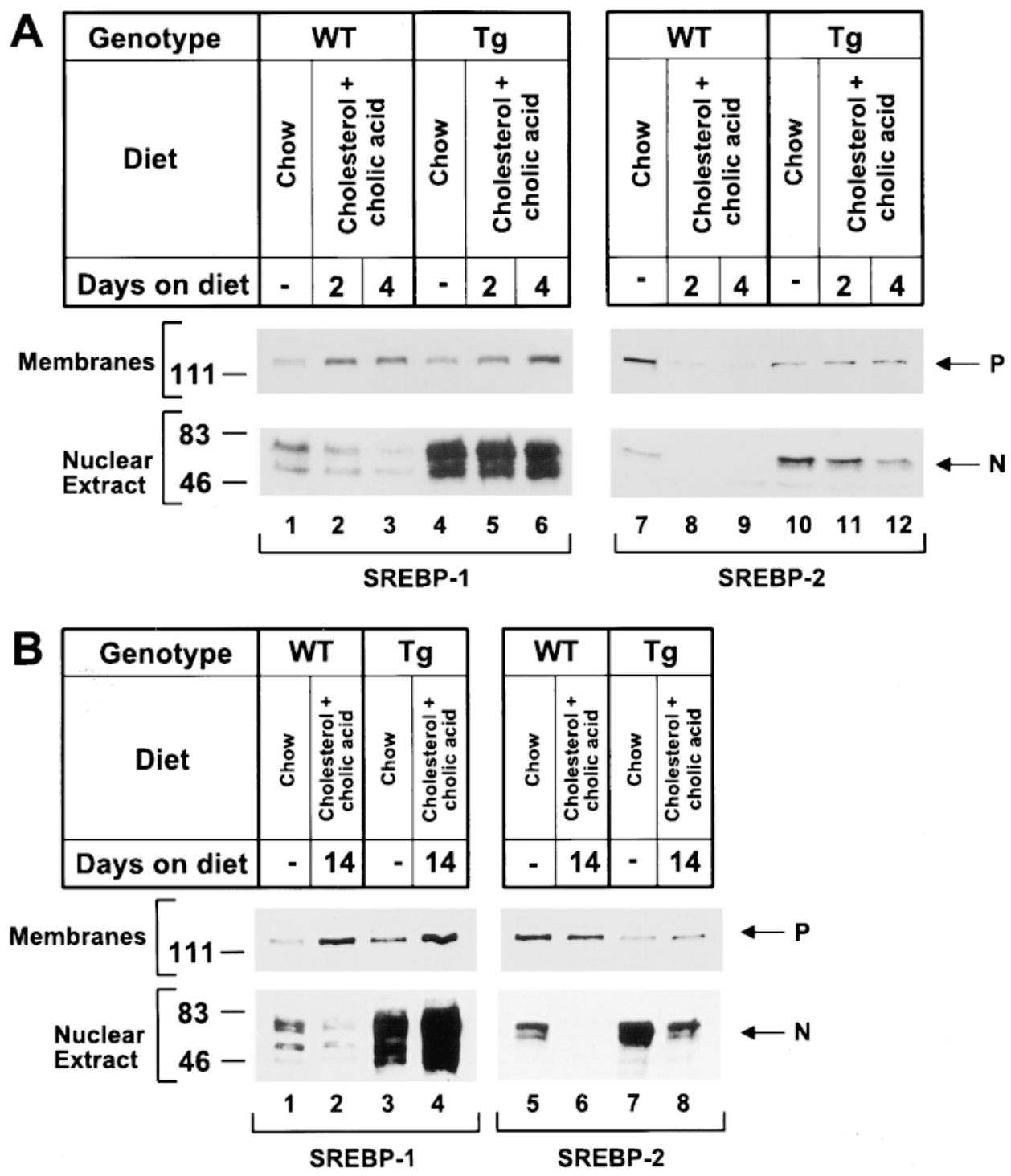

Figure 8. Immunoblot analysis of SREBP-1 and SREBP-2 in membranes and nuclear extracts from livers of wild-type and SCAP(D443N) transgenic male mice on different diets. $(A)$ Mice were placed on the standard chow diet (lanes 1, 4, 7, and 10 ) or chow diet supplemented with $1 \%$ cholesterol and $0.5 \%$ cholic acid for either $2 \mathrm{~d}$ (lanes 2, 5, 8, and 11 ) or $4 \mathrm{~d}$ (lanes $3,6,9$, and 12) as indicated. The diets were begun in a staggered fashion so that all mice could be killed at the same time.

Livers from four wild-type and four TgSCAP(D443N) mice/treatment group were pooled, and aliquots of the membrane $(50 \mu \mathrm{g})$ and nuclear extract $(30 \mu \mathrm{g})$ fractions were subjected to $8 \%$ SDS-PAGE. Immunoblot analysis was performed using 5 $\mu \mathrm{g} / \mathrm{ml}$ of rabbit anti-mouse SREBP-1 IgG (lanes 1-6) or SREBP-2 IgG (lanes 7-12) as the primary antibody. Filters were exposed to film (Reflection ${ }^{\mathrm{TM}}$ NEF 496; New England Nuclear) for $15 \mathrm{~s}$ (lanes 1-6) and $20 \mathrm{~s}$ (lanes 7-12) at room temperature. (B) Mice were placed on the standard chow diet (lanes 1,3,5, and 7) or the chow diet supplemented with $0.5 \%$ cholesterol and $0.25 \%$ cholic acid for $14 \mathrm{~d}$ (lanes 2 , 4,6 , and 8 ). Immunoblot analysis was performed as described above. Filters were exposed to film for $20 \mathrm{~s}$ (lanes 1-4) and $45 \mathrm{~s}$ (lanes 5-8) at room temperature. $P$ and $N$ denote the precursor and cleaved nuclear forms of SREBP, respectively. 
nSREBP-2 (Fig. $8 \mathrm{~B}$, lane 8 ) $(50 \%$ as determined by densitometric scanning).

To examine the regulation of the SREBP target genes in the cholesterol-fed animals, total RNA was isolated from livers of wild-type and transgenic mice that had been fed $1 \%$ cholesterol/ $/ 0.5 \%$ cholic acid for $2 \mathrm{~d}$ (2-d animals from Fig. $8 A$ ). In wild-type mice, this diet produced $30-60 \%$ reductions in the mRNAs for HMG CoA synthase, farnesyl diphosphate synthase, and squalene synthase (Fig. 9). The amount of HMG CoA reductase mRNA was too low for accurate measurement. The LDL receptor mRNA decreased by only $20 \%$. The mRNA levels for the fatty acid synthetic enzymes acetyl CoA carboxylase, fatty acid synthase, and SCD were either unchanged or slightly reduced with the cholesterol diet. In the SCAP(D443N) transgenic mice, the mRNAs for the cholesterol synthetic enzymes were also decreased, but they remained much higher than was seen in the chow-fed wild-type mice. Fig. 9 also gives the values obtained from quantitative analysis of the Northern blots of total RNA isolated from livers of wild-type and transgenic mice that had been fed the $0.5 \%$ cholesterol $/ 0.25 \%$ cholic acid diet for $14 \mathrm{~d}(*)$. The results were similar to those seen at $2 \mathrm{~d}$.

\section{Discussion}

The data presented in this paper implicate SCAP as the gatekeeper that enforces feedback regulation of cholesterol synthesis in mouse liver. When the liver expressed a mutant version of SCAP that is resistant to feedback suppression by sterols, the amounts of nSREBP- 1 and -2 rose markedly and there was a concomitant increase in the amounts of mRNAs derived from multiple genes in the pathways of cholesterol and fatty acid biosynthesis. Overproduction of cholesterol and fatty acids led to marked engorgement of the liver with cholesteryl esters and triglycerides, and yet the rates of lipid synthesis remained high. These results were similar to those previously observed in transgenic mice that overexpress truncated dominant positive nSREBPs that enter the nucleus without proteolysis and are therefore immune from SCAP-mediated downregulation $(34,35,43)$. Considered together, the results indicate that tonic suppression of SREBP cleavage, mediated by the sterol-sensing domain of SCAP, is necessary to prevent overproduction of lipids in the liver.

In these experiments, the expression of the SCAP transgene was driven by the PEPCK promoter, which produces a moder-
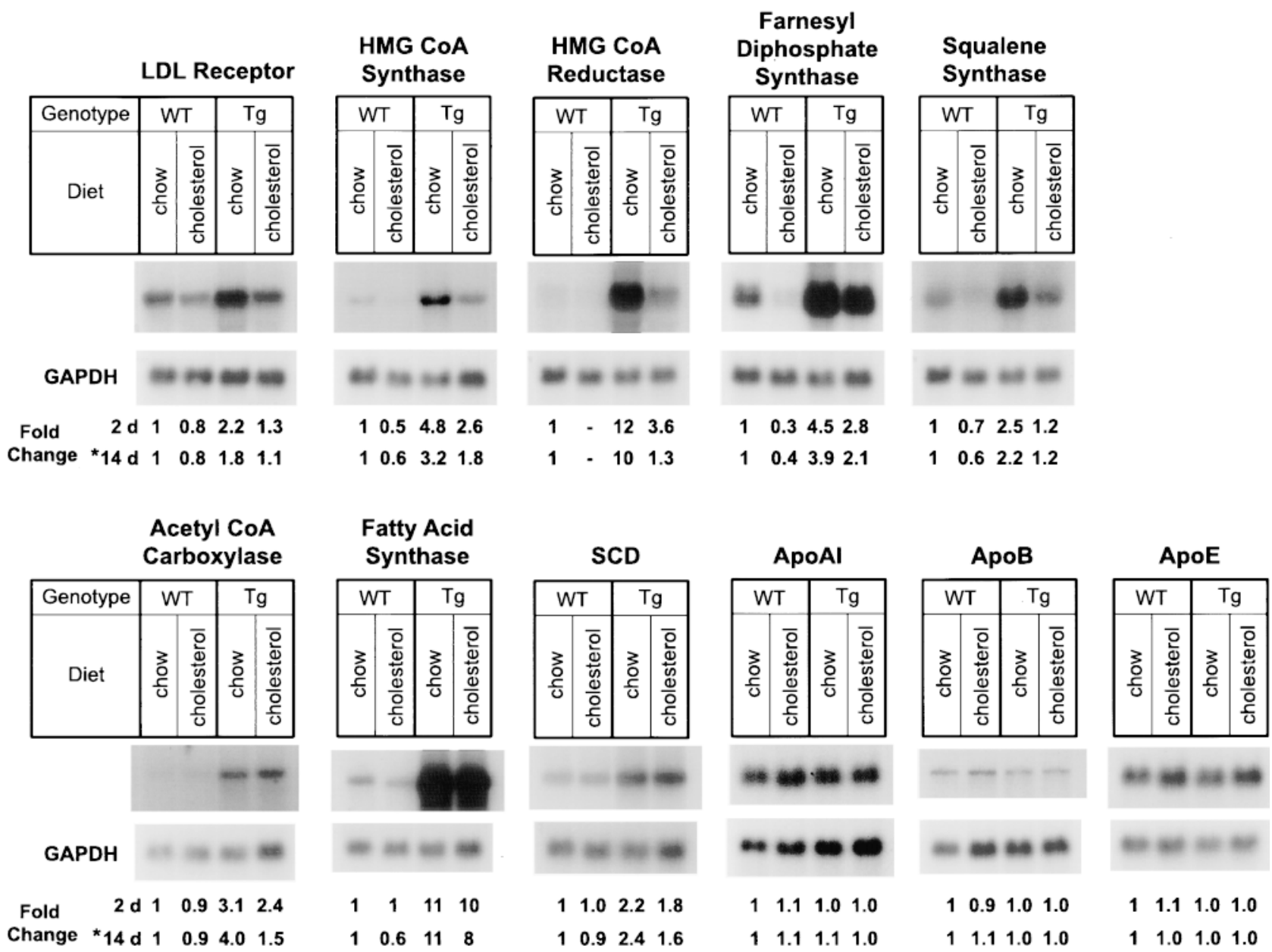

Figure 9. Amounts of various mRNAs in livers of wild-type and TgSCAP(D443N) mice on different diets. Total RNA was isolated from mice fed a chow diet or a chow diet supplemented with either $1 \%$ cholesterol $/ 0.5 \%$ cholic acid for $2 \mathrm{~d}$ (Table IV 2 -d animals) or $0.5 \%$ cholesterol/ $0.25 \%$ cholic acid for $14 \mathrm{~d}$ (Table IV 14-d animals). The mRNA was subjected to blot hybridization and quantified as described in Fig. 5. The mRNA data for the 2-d animals is shown with the fold change calculations shown below it. *The fold change data for the 14-d animals. 
ate level of expression in the liver when the mice eat a standard chow diet. The PEPCK promoter can be induced further by feeding the animals a low carbohydrate/high protein diet (26). We deliberately avoided this diet in these studies because we wished to maintain the level of mutant SCAP(D443N) expression within a relatively physiologic range. Indeed, quantitative measurements of mRNA levels revealed that the amount of SCAP(D443N) mRNA derived from the transgene was only $30 \%$ of the amount derived from the wild-type gene in the transgenic mouse liver (Fig. 2). Despite this low level of expression, the mutant SCAP was able to stimulate cleavage of both SREBP-1 and SREBP-2 and to render this cleavage partially resistant to feedback regulation by dietary cholesterol.

In the transgenic mice, cholesterol feeding dissociated the regulation of SREBP-1 and SREBP-2, and the experiments therefore provide some information about the individual roles of these two transcription factors in the liver. When wild-type mice were fed a cholesterol/cholic acid diet, the amount of nSREBP-2 declined to unmeasurable levels within $2 \mathrm{~d}$ (Fig. 8). The amount of nSREBP-1 was also reduced, but less completely. In the SCAP(D443N) transgenic animals, the cholesterol/cholic acid diet did not eliminate nSREBP-2, but it did reduce it partially. nSREBP-1 was not decreased, and it even appeared to be slightly increased. The amounts of the mRNAs for the cholesterol and fatty acid biosynthetic enzymes tended to parallel the amounts of nSREBP-2, rather than nSREBP-1. In the transgenic mice, the levels of these mRNAs, as well as that for the LDL receptor, declined partially after cholesterol feeding, suggesting that their transcription was being driven primarily by nSREBP-2, and not by nSREBP-1, which remained elevated. This finding is consistent with the observation that SREBP-1c is the predominant form of SREBP-1 in both the wild-type and transgenic livers (Fig. 4). Transgenic animals overexpressing truncated dominant positive SREBP$1 \mathrm{c}$ have much less elevation in target gene mRNAs than do the animals expressing truncated SREBP-2, indicating that SREBP-2 is a more potent activator of transcription than is SREBP-1c in liver $(35,43)$ as it is in cultured cells $(44)$.

This data also lend support to the notion that the SREBPs play different roles in regulating cholesterol synthesis than they do in regulating fatty acid synthesis. When wild-type mice were fed cholesterol, there was a marked decline in nSREBPs, and this was accompanied by a clear decline in the mRNAs for at least four enzymes in the cholesterol biosynthetic pathway (Fig. 9). On the other hand, there was much less decline in the mRNAs for acetyl CoA carboxylase and fatty acid synthase. These data support the concept that basal transcription of the fatty acid-synthesizing enzymes is driven primarily by factors other than SREBPs, whereas the cholesterologenic enzymes are more dependent upon SREBPs, even in the basal state (2, $44)$. Both of these pathways can be activated further by elevated levels of nSREBPs. These findings are similar to those in cultured cells. Cultured cells with defects in SREBP processing have a complete absence of cholesterol synthesis, but only a partial reduction of fatty acid synthesis (44).

In the TgSCAP(D443N) mice, the levels of mRNA for SREBP-1 and SREBP-2 were elevated (Fig. 5). This suggests that there may be a feed-forward system by which elevated levels of nSREBPs induce transcription of their own genes. Indeed, Sato et al. (45) showed that transfected nSREBP-2 activates a reporter construct driven by the native promoter region of the human SREBP-2 gene $(-140$ to $+172 \mathrm{bp})$.
Despite the massive elevation in hepatic lipids in the SCAP(D443N) transgenic mice, the levels of cholesterol and triglycerides in plasma were below normal (Table I). This is similar to previous observations in transgenic mice expressing truncated dominant positive SREBP-1a (34) and SREBP-2 (43). It is possible that these mice do synthesize increased amounts of lipid-enriched lipoproteins, but that the plasma level is kept low because of rapid clearance mediated by the elevated LDL receptors. Alternatively, the transgenic livers may secrete less lipoproteins. Answers to these questions should emerge from cross-breeding experiments between the various SREBP transgenics and homozygous LDL receptor-deficient mice (46).

\section{Acknowledgments}

We thank our colleague Hitoshi Shimano for helpful discussions, Scott Clark and Debra Morgan for excellent technical assistance, Shan Maika and Beth Hinnant for superb genotyping of mice, Richard Gibson for invaluable help with the animals, and Maz Hasan for kindly providing the $\mathrm{pRI}_{2}$-intronA plasmid.

This work was supported by research grants from the National Institutes of Health (HL20948), the Moss Heart Foundation, and the Perot Family Foundation. B.S. Korn is supported by Medical Scientist Training grant GM08014. I. Shimomura is the recipient of a research fellowship from the Manpei Suzuki Diabetes Foundation of Tokyo, Japan. J.D. Horton was the recipient of a postdoctoral fellowship for physicians from the Howard Hughes Medical Institute.

\section{References}

1. Gould, R.G., C.B. Taylor, J.S. Hagerman, I. Warner, and D.J. Campbell. 1953. Cholesterol metabolism: effect of dietary cholesterol on the synthesis of cholesterol in dog tissue in vitro. J. Biol. Chem. 201:519-523.

2. Brown, M.S., and J.L. Goldstein. 1997. The SREBP pathway: regulation of cholesterol metabolism by proteolysis of a membrane-bound transcription factor. Cell. 89:331-340.

3. Duncan, E.A., M.S. Brown, J.L. Goldstein, and J. Sakai. 1997. Cleavage site for sterol-regulated protease localized to a Leu-Ser bond in luminal loop of sterol regulatory element binding protein-2. J. Biol. Chem. 272:12778-12785.

4. Duncan, E.A., U.P. Davé, J. Sakai, J.L. Goldstein, and M.S. Brown. 1998. Second-site cleavage in sterol regulatory element-binding protein occurs at transmembrane junction as determined by cysteine panning. J. Biol. Chem. 273: 17801-17809.

5. Yokoyama, C., X. Wang, M.R. Briggs, A. Admon, J. Wu, X. Hua, J.L. Goldstein, and M.S. Brown. 1993. SREBP-1, a basic helix-loop-helix leucine zipper protein that controls transcription of the LDL receptor gene. Cell. 75 : 187-197.

6. Hua, X., C. Yokoyama, J. Wu, M.R. Briggs, M.S. Brown, J.L. Goldstein, and X. Wang. 1993. SREBP-2, a second basic-helix-loop-helix-leucine zipper protein that stimulates transcription by binding to a sterol regulatory element. Proc. Natl. Acad. Sci. USA. 90:11603-11607.

7. Ericsson, J., S.M. Jackson, and P.A. Edwards. 1996. Synergistic binding of sterol regulatory element-binding protein and NF-Y to the farnesyl diphosphate synthase promoter is critical for sterol-regulated expression of the gene. J. Biol. Chem. 271:24359-24364.

8. Guan, G., P. Dai, and I. Shechter. 1998. Differential transcriptional regulation of the human squalene synthase gene by sterol regulatory element-binding proteins (SREBP) $1 \mathrm{a}$ and 2 and involvement of 5' DNA sequence elements in the regulation. J. Biol. Chem. 273:12526-12535.

9. Kim, J.B., G.D. Spotts, Y.-D. Halvorsen, H.-M. Shih, T. Ellenberger, H.C. Towle, and B.M. Spiegelman. 1995. Dual DNA binding specificity of ADD1/SREBP1 controlled by a single amino acid in the basic helix-loop-helix domain. Mol. Cell Biol. 15:2582-2588.

10. Bennett, M.K., J.M. Lopez, H.B. Sanchez, and T.F. Osborne. 1995. Sterol regulation of fatty acid synthase promoter: coordinate feedback regulation of two major lipid pathways. J. Biol. Chem. 270:25578-25583.

11. Kim, J.B., and B.M. Spiegelman. 1996. ADD1/SREBP1 promotes adipocyte differentiation and gene expression linked to fatty acid metabolism. Genes Dev. 10:1096-1107.

12. Lopez, J.M., M.K. Bennett, H.B. Sanchez, J.M. Rosenfeld, and T.F. Osborne. 1996. Sterol regulation of acetyl CoA carboxylase: a mechanism for coordinate control of cellular lipid. Proc. Natl. Acad. Sci. USA. 93:1049-1053. 
13. Ericsson, J., S.M. Jackson, J.B. Kim, B.M. Spiegelman, and P.A. Edwards. 1997. Identification of glycerol-3-phosphate acyltransferase as an adipocyte determination and differentiation factor 1 - and sterol regulatory elementbinding protein-responsive gene. J. Biol. Chem. 272:7298-7305.

14. Tabor, D.E., J.B. Kim, B.M. Spiegelman, and P.A. Edwards. 1998. Transcriptional activation of the stearoyl-CoA desaturase 2 gene by sterol regulatory element-binding protein/adipocyte determination and differentiation factor 1. J. Biol. Chem. 273:22052-22058.

15. Wang, X., R. Sato, M.S. Brown, X. Hua, and J.L. Goldstein. 1994 SREBP-1, a membrane-bound transcription factor released by sterol-regulated proteolysis. Cell. 77:53-62.

16. Hua, X., A. Nohturfft, J.L. Goldstein, and M.S. Brown. 1996. Sterol resistance in $\mathrm{CHO}$ cells traced to point mutation in SREBP cleavage activating protein (SCAP). Cell. 87:415-426.

17. Nohturfft, A., M.S. Brown, and J.L. Goldstein. 1998. Topology of SREBP cleavage-activating protein, a polytopic membrane protein with a sterol-sensing domain. J. Biol. Chem. 273:17243-17250.

18. Neer, E.J., C.J. Schmidt, R. Nambudripad, and T.F. Smith. 1994. The ancient regulatory-protein family of WD-repeat proteins. Nature. 371:297-300.

19. Sakai, J., A. Nohturfft, J.L. Goldstein, and M.S. Brown. 1998. Cleavage of sterol regulatory element binding proteins (SREBPs) at site-1 requires interaction with SREBP cleavage-activating protein. Evidence from in vivo competition studies. J. Biol. Chem. 273:5785-5793.

20. Nohturfft, A., M.S. Brown, and J.L. Goldstein. 1998. Sterols regulate processing of carbohydrate chains of wild-type SREBP cleavage-activating protein (SCAP), but not sterol-resistant mutants Y298C or D443N. Proc. Natl. Acad. Sci. USA. 95:12848-12853.

21. Gil, G., J.R. Faust, D.J. Chin, J.L. Goldstein, and M.S. Brown. 1985. Membrane-bound domain of HMG CoA reductase is required for sterolenhanced degradation of the enzyme. Cell. 41:249-258.

22. Olender, E.H., and R.D. Simoni. 1992. The intracellular targeting and membrane topology of 3-hydroxy-3-methylglutaryl-CoA reductase. J. Biol. Chem. 267:4223-4235.

23. Chang, T.-Y., and J.S. Limanek. 1980. Regulation of cytosolic acetoacetyl coenzyme A thiolase, 3-hydroxy-3-methylglutaryl coenzyme A synthase, 3-hydroxy-3-methylglutaryl coenzyme A reductase, and mevalonate kinase by low density lipoprotein and by 25 -hydroxycholesterol in Chinese hamster ovary cells. J. Biol. Chem. 255:7787-7795.

24. Yokode, M., R.E. Hammer, S. Ishibashi, M.S. Brown, and J.L. Goldstein. 1990. Diet-induced hypercholesterolemia in mice: prevention by overexpression of LDL receptors. Science. 250:1273-1275.

25. Bucolo, G., and H. David. 1973. Quantitative determination of serum triglycerides by the use of enzymes. Clin. Chem. 19:476-482

26. Short, M.K., D.E. Clouthier, I.M. Schaefer, R.E. Hammer, M.A. Magnuson, and E.G. Beale. 1992. Tissue-specific, developmental, hormonal, and dietary regulation of rat phosphoenolpyruvate carboxykinase-human growth hormone fusion genes in transgenic mice. Mol. Cell Biol. 12:1007-1020.

27. Palmiter, R.D., E.P. Sandgren, M.R. Avarbock, D.D. Allen, and R.L. Brinster. 1991. Heterologous introns can enhance expression of transgenes in mice. Proc. Natl. Acad. Sci. USA. 88:478-482.

28. Hofmann, S.L., D.W. Russell, M.S. Brown, J.L. Goldstein, and R.E. Hammer. 1988. Overexpression of low density lipoprotein (LDL) receptor eliminates LDL from plasma in transgenic mice. Science. 239:1277-1281.

29. Chen, C.W., and C.A. Thomas, Jr. 1980. Recovery of DNA segments from agarose gels. Anal. Biochem. 101:339-341.

30. Sheng, Z., H. Otani, M.S. Brown, and J.L. Goldstein. 1995. Independent regulation of sterol regulatory element binding proteins 1 and 2 in hamster liver. Proc. Natl. Acad. Sci. USA. 92:935-938.

31. Shimano, H., I. Shimomura, R.E. Hammer, J. Herz, J.L. Goldstein, M.S Brown, and J.D. Horton. 1997. Elevated levels of SREBP-2 and cholesterol synthesis in livers of mice homozygous for a targeted disruption of the SREBP-1 gene. J. Clin. Invest. 100:2115-2124.

32. Shimomura, I., H. Shimano, J.D. Horton, J.L. Goldstein, and M.S. Brown. 1997. Differential expression of exons 1a and 1c in mRNAs for sterol regulatory element binding protein-1 in human and mouse organs and cultured cells. J. Clin. Invest. 99:838-845.

33. Shimomura, I., H. Shimano, B.S. Korn, Y. Bashmakov, and J.D. Horton. 1999. Nuclear sterol regulatory element-binding proteins activate genes responsible for the entire program of unsaturated fatty acid biosynthesis in transgenic mouse liver. J. Biol. Chem. In press.

34. Shimano, H., J.D. Horton, R.E. Hammer, I. Shimomura, M.S. Brown, and J.L. Goldstein. 1996. Overproduction of cholesterol and fatty acids causes massive liver enlargement in transgenic mice expressing truncated SREBP-1a. J. Clin. Invest. 98:1575-1584.

35. Shimano, H., J.D. Horton, I. Shimomura, R.E. Hammer, M.S. Brown, and J.L. Goldstein. 1997. Isoform 1c of sterol regulatory element binding protein is less active than isoform 1a in livers of transgenic mice and in cultured cells. J. Clin. Invest. 99:846-854.

36. Goldstein, J.L., S.E. Dana, J.R. Faust, A.L. Beaudet, and M.S. Brown. 1975. Role of lysosomal acid lipase in the metabolism of plasma low density lipoprotein: observations in cultured fibroblasts from a patient with cholesteryl ester storage disease. J. Biol. Chem. 250:8487-8495.

37. Hamilton, J.G., and K. Comai. 1988. Rapid separation of neutral lipids, free fatty acids and polar lipids using prepacked silica Sep-pak columns. Lipids. 23:1146-1149.

38. Lepage, G., and C.C. Roy. 1986. Direct transesterification of all classes of lipids in a one-step reaction. J. Lipid Res. 27:114-120.

39. Woollett, L.A., D.K. Spady, and J.M. Dietschy. 1992. Regulatory effects of the saturated fatty acids 6:0 through 18:0 on hepatic low density lipoprotein receptor activity in the hamster. J. Clin. Invest. 89:1133-1141.

40. Kaestner, K.H., J.M. Ntambi, T.J. Kelly, Jr., and M.D. Lane. 1989. Differentiation-induced gene expression in 3T3-L1 preadipocytes. A second differentially expressed gene encoding stearoyl-CoA desaturase. J. Biol. Chem. 264: 14755-14761.

41. Ntambi, J.M. 1995. The regulation of stearoyl-CoA desaturase (SCD). Prog. Lipid Res. 34:139-150.

42. Russell, D.W., and K.D.R. Setchell. 1992. Bile acid biosynthesis. Biochemistry. 31:4737-4749.

43. Horton, J.D., I. Shimomura, M.S. Brown, R.E. Hammer, J.L. Goldstein, and H. Shimano. 1998. Activation of cholesterol synthesis in preference to fatty acid synthesis in liver and adipose tissue of transgenic mice overproducing SREBP-2. J. Clin. Invest. 101:2331-2339.

44. Pai, J.-T., O. Guryev, M.S. Brown, and J.L. Goldstein. 1998. Differential stimulation of cholesterol and unsaturated fatty acid biosynthesis in cells expressing individual nuclear sterol regulatory element binding proteins. J. Biol. Chem. 273:26138-26148.

45. Sato, R., J. Inoue, Y. Kawabe, T. Kodama, T. Takano, and M. Maeda. 1996. Sterol-dependent transcriptional regulation of sterol regulatory elementbinding protein-2. J. Biol. Chem. 271:26461-26464.

46. Ishibashi, S., M.S. Brown, J.L. Goldstein, R.D. Gerard, R.E. Hammer, and J. Herz. 1993. Hypercholesterolemia in LDL receptor knockout mice and its reversal by adenovirus-mediated gene delivery. J. Clin. Invest. 92:883-893. 